\title{
CATEGORIA DE GÊNERO NA ENFERMAGEM
}

\author{
GENDER CATEGORIE IN NURSING \\ CATEGORIAA DE GÉNERO EN LA ENFERMERIA
}

\author{
Alcione Leite da Silva' \\ Patrícia Corrêa ${ }^{2}$
}

\begin{abstract}
RESUMO: Este estudo teve por objetivo analisar as categorias de gênero, a partir de periódicos sobre estudo de gênero na enfermagem brasileira. Usando uma abordagem exploratória, analisamos os artigos na área, publicados em dez periódicos nacionais de enfermagem, no periodo de 1955 a 1997/1. Com base na análise dos discursos, as categorias centrais para as quais convergiram as atençöes das/os autoras/es foram: gênero e determinantes históricos e sociais no desenvolvimento da profissão de enfermagem, gênero e trabalho, gênero e saúde, gênero e educação e gênero e feminismo. Outras perspectivas importantes, menos enfatizadas, mas emergentes na literatura de enfermagem foram: gênero e cuidado, gênero e família, gênero e violência.
\end{abstract}

PALAVRAS-CHAVE: gênero, Enfermagem.

\section{INTRODUÇÃO}

Uma explosão de publicações, tendo gênero como foco central, vem ocorrendo, no Brasil, desde o final da década de 80 , colocando as mulheres no centro da análise e critica do sistema androcêntrico/falocêntrico do conhecimento, no qual as experiências e prioridades dos homens têm sido tradicionalmente centrais e representativas do todo (Silva, 1997). Tal fato demonstra a história recente da incorporação do conceito de gênero nos estudos das diversas academias, no Brasil. Neste sentido, como bem assinala Machado (1992), temos que considerar que a possibilidade politica de emergência da luta pelos direitos de "minorias", pelos direitos de alteridade, só se configurou no Brasil, no espaço inicial da abertura politica.

Algumas academias vêm se destacando pelos estudos pioneiros nesta área, como é o caso das Ciências Sociais e dos estudos de Literatura e critica literária que, a partir, do final de 80 , postularam a primazia dos estudos de gênero sobre os estudos da mulher e a "superação" dos estudos dos papéis sexuais pelos de gênero (Hollanda, 1992). Em outras academias, esta abordagem é ainda mais recente e incipiente, como é o caso da educação, em que foi evidenciada a escassez de pesquisas analisando as relaçöes de gênero (Rosemberg, 1992) e da história, na qual o conceito de gênero ainda fica submerso em pesquisas que têm se dedicado muito mais à história das mulheres (Pedro, 1994). Na enfermagem brasileira, Pereira (1996), embora não faça um estudo sistemático da literatura, coloca que apesar da variedade de reflexões publicadas e de dissertações e teses

${ }^{1}$ Doutora em Filosofia da Enfermagem e professora Titular do Depto. de Enfermagem da UFSC, Coordenadora Didático-Pedagógica do Mestrado de Enfermagem da UFSC e Mestrados Expandidos e Pesquisado do CNPq.

${ }^{2}$ Aluna da $7^{a}$ fase curricular do Curso de Graduação em Enfermagem da UFSC. 
defendidas, nas últimas décadas, retratar as várias experiências e situações da mulher na saúde, no ensino, dentro e fora da enfermagem, evidencia-se poucas publicaçōes utilizando gênero como referencial de análise.

Considerando as importantes contribuiçōes que os estudos de gênero podem trazer para a disciplina profissional da enfermagem, através de sua prática e educação, bem como para a construção do seu corpo de conhecimento, este estudo tem por objetivo analisar as categorias de gênero, a partir dos periódicos sobre estudo de gênero na enfermagem brasileira.

Dada a característica deste estudo exploratório, a produção acadêmica para análise se restringiu aos artigos na área de gênero, publicados em dez periódicos nacionais da enfermagem, no periodo de 1955 a 1997/1, a saber: Revista Brasileira de Enfermagem (Brasilia - GO); Revista de Enfermagem da USP (São Paulo - SP); Revista Gaúcha de Enfermagem (Porto Alegre - RS); Revista Baiana de Enfermagem (Salvador - BA); Revista Paulista de Enfermagem (São Paulo - SP); Revista Acta-Paulista de Enfermagem (São Paulo - SP), Revista Texto e Contexto - Enfermagem (Florianópolis - SC); Revista Latinoamericana de Enfermagem (Riebriāo Preto - SP); Revista de Enfermagem da UERJ (Rio de Janeiro $\mathrm{RJ}$ ); e Revista Cogitare Enfermagem (Curitiba - PR). Procuramos, assim, incluir a maioria dos periódicos existentes na enfermagem brasileira. Considerando que a maioria destes periódicos são originários das regiões sul e sudeste, estas foram mais contempladas na investigação.

Os critérios utilizados na seleção do artigos incluiram: 1) aqueles que apesar de não explicitar o conceito de gênero, recuperam no interior de suas análises aspectos relativos às relações de gênero, tais como: as relaçōes desiguais na divisão social e técnica do trabalho da/o enfermeira/o, e a relação e os limites da atuação profissional; e 2) aqueles que explicitam a dimensăo relacional de gênero, quer enquanto categoria analitica, que enquanto processo social, procurando captar a trama das relações sociais, bem como as transformações históricas sofridas por elas, através dos processos sociais. A análise dos conteúdos foi conduzida a partir do referencial de Bardin (1979). Deste modo, com base na leitura dos artigos, procuramos, através de procedimentos sistemáticos, identificar, na prática discursiva, as categorias centrais para as quais convergiram as atenções das/os autoras/es.

Chamamos a atenção para os limites deste estudo, tendo em vista que a publicação dos periódicos reflete em parte o estado da arte sobre o tema na enfermagem.

O número de artigos selecionados totalizaram sessenta e três ${ }^{3}$, resultantes, na sua grande maioria de reflexões teóricas, o que evidencia a escassez de estudos englobando as relações de gênero na enfermagem. Na sua quase totalidade, foram escritos por docentesenfermeiras, enquanto alunas de pós-graduação, com destaque para as doutorandas, bem como por doutoras e mestres em enfermagem. Outro fato que merece também ser destacado é a quase ausência de estudos que busquem o diálogo interdisciplinar, principalmente quando consideramos ser este um campo eminentemente interdisciplinar. Somente em nove estudos, as autoras afirmaram como razão do trabalho a participação em úcleos de pesquisa na área ${ }^{4}$.

${ }^{3}$ Merece atenção aqui o fato de termos encontrado três artigfos publicados simultaneamente em dois periódicos, bem como de três dos estudos serem de autorias de profissionais de outras áreas do conhecimento.

4 Destacamos que mais de $50 \%$ dos artigos provém dos Núcleos de Estudos da região Nordeste, tais como: Núcleo de Estudos Interdisciplinares sobre a mulher - NEIM-FCH-UFBA; Grupo de Estudos sobre Saúde da Mulher - GEM-EE-UFBA; Núcleo de Estudos Mulher e Saúde MUSA-DMP-UFBA. O restante provém da região Sudeste, Núcleo de Estudos da Mulher e Relações Sociais de Gênero - NEMGE-USP. 


\section{CONSIDERAÇÕES SOBRE O CONCEITO DE GÊNERO}

Considerando o universo do estudo, a categoria de gênero tem história recente na enfermagem, tendo em vista que mais de $50 \%$ da população acadêmica sobre estudos de gênero se concentram nos anos de 1996 e 1997. Apesar do número pouco significativo de artigos, no final da década de 70 e no decorrer da década de 80 , recuperar no interior de suas análises, aspectos relativos às relações desiguais na divisão social e técnica do trabalho da/ o enfermeira/o e a relação e os limites da atuação profissional, eles não explicitam e definem o conceito de gênero. Este conceito inicia a ser utilizado na literatura, sob investigação, a partir da década de 90 , sendo que poucos estudos explicitam uma definiçäo. Contudo, as teorizações sobre gênero evidenciam as

Inúmeras tramas teóricas, nas quais ele tem sido articulado. A historiadora Guacira Louro (1996) esclarece bem esta questão, quando questiona: estão todas as autoras falando da mesma coisa quando falam em gênero? Que sentidos e quantos sentidos estão contidos nesta explicação? De onde ela surge? O que pretendem designar e o que instituem? Segundo Louro (1996), o conceito de gênero tem sido utilizado por estudiosas/os marxistas, pósestruturalistas, lacanianas/os, feministas radicais e tantas outras e outros que não pretendem qualquer classificação. Talvez exatamente por estas diferentes apropriaçōes, afirma Louro (1996), o conceito tem sido constantemente debatido, o que acaba por representar tanto um fator de instabilidade, quando de vitalidade. Deste modo, concordamos com Louro (1996), de que a opção pelo conceito de gênero significa uma decisão de ordem epistemológica, implica em opção teórica.

As definiçōes do conceito de gênero, explicitas pelas/os autoras/es dos éstudos sobre investigação, como é o caso de Lunardi (1993), Lima (1995), Pereira (1996), Xavier (1996) e Fonseca $(1997 a, b)$, apontam na direção do pensamento de Joan Scott, estudiosa feminista e historiadora influente nos estudos de gênero no Brasil e exterior. Scott apoia-se em algumas teorizações pós-estruturalistas e, dentre elas, a de desconstrução, proposta por Derrida, para pensar as questões do gênero. Como outras/os, esta pesquisadora entende o conceito de gênero como uma construção social, uma interpretação social do biológico, não se relacionando a uma visão funcionalista da sexualidade. Segundo Scott (1988), o núcleo de definições de gênero reside em uma conexão integral entre duas proposiçōes: gênero é um elemento constitutivo das relaçŏes sociais, baseado em diferenças percebidas entre os sexos, e gênero é a maneira primordial de significar relaçōes de poder, em que as representações dominantes são apresentadas como naturais e inquestionáveis.

Uma das propostas interessantes de Scott, bem como de outras estudiosas, como é o caso de Louro (1996), é a desconstrução da lógica das operações binárias e, a partir dai, desconstruir a lógica dos sistemas tradicionais de pensamento. Neste sentido, Scott (1990), defende a necessidade de uma rejeição do caráter fixo e permanente da oposição binária, de uma históricização e de uma desconstrução autênticas dos termos da diferença sexual. A partir da desconstrução da polaridade masculino/feminino, é possivel desmontar toda uma lógica binária que rege outros pares de conceitos a ela articulados, como por exemplo: público/privado, pessoal/politico, produção/reprodução, cultura/natureza, dentre outros.

As recente teorizações sobre gênero extrapolam as oposições binárias entre os pólos homem/mulher e masculino/feminino, como é o caso do pós-feminismo, ao se perguntar sobre as diferenças e as relações não só entre homens e mulheres, mas também entre mulheres (Costa; Bruschini, 1992). Já para Louro (1997), a proposta de desconstrução implicaria em problematizar não só a oposição entre homem/mulher, mas também a unidade interna de cada um, evidenciando que cada polo existe em relação e suposição do outro, 
estando eles internamente divididos, uma vez que não somos apenas mulheres e homens, mas reunimos inúmeros marcadores articulados (como por ex. brancos/as, negros/as, jovens, velhos/as, católicos, protestantes), que nos posicionam de forma diferenciada no contexto social.

Embora não contempladas nos artigos examinados, as recentes teorizaçöes sobre gênero ampliam, sobremaneira, o campo de análise dos estudos na enfermagem. Concordamos, assim, com Saffioti (1992), de que a construção de gênero pode ser compreendida como um processo infinito de modelagem-conquista dos seres humanos, que tem lugar na trama de relações sociais entre mulheres, entre homens e entre mulheres e homens. Nesta perspectiva, o resgate de uma ontologia relacional deve ser parte integrante de uma maneira feminina de fazer ciência.

\section{CATEGORIAS CENTRAIS DAS RELAÇŌES DE GÊNERO}

As categorias de relações de gênero enfatizadas na produção acadêmica foram: gênero e determinantes históricos e sociais no desenvolvimento da profissão de enfermagem, gênero e trabalho, gênero e saúde, gênero e educação, e gênero e feminismo. Ao se configurarem em uma teia de interrelaçőes, muitas destas categorias são tecidas no conjunto das reflexōes analisadas. Apresentamos, a seguir, uma análise dos discursos encontrados:

\section{GÊNERO E DETERMINANTES HISTÓRICOS E SOCIAIS NO DESENVOLVIMENTO DA PROFISSĀO DE ENFERMAGEM}

Historicamente, a enfermagem moderna se constrói em meio ao surgimento de um movimento feminista, em fins do século XVIII, que tomará corpo, já no século XIX, na maioria dos paises europeus e nos Estados Unidos. Podemos considerar que, em parte, na época, tinha como principal bandeira a luta pela igualdade de direitos juridicos entre os sexos e a liberdade de trabalho. Tanto a enfermagem, como o feminismo liberal emergem liderados por mulheres de classe mais abastadas, que tiveram acesso à educação superior. Contudo, o seu desenvolvimento parece se afastar daquele movimento de origem, o que se reflete nas caracteristicas históricas de submissão, opressão, e marginalização, que ainda marcam a nossa profissão. A despeito deste fato, năo podemos relegar ao esquecimento a presença de inúmeras feministas na enfermagem no decorrer de sua história.

No que se refere à enfermagem brasileira, o seu surgimento se dá posteriormente à introdução do pensamento feminista no Brasil, no século passado, sendo que não parece haver indicios de qualquer ligação entre ambos. Mesmo após a década de 60 , quando se observa uma intensa mobilização sócio-politica em diferentes partes do mundo e a expansão de estudos feministas nos Estados Unidos e em paises da Europa e da América Latina, entre estes, o Brasil, não se observa tais reflexos na enfermagem. Principalmente, quando consideramos que a adoção da vertente feminista é recente na enfermagem norte-americana e mais ainda na enfermagem brasileira.

Contudo, cabe ressaltarmos que o mesmo não aconteceu com os estudos de gênero, o qual vem avançando paulatinamente na enfermagem. Após a discussão inicial em 1979 no Congresso Brasileiro de Enfermagem - CBEn, realizado em Fortaleza, em 1986, o CBEn, realizado no Rio, retoma o tema de gênero e em 1987 é realizado em Salvado como atividade pré-congresso, uma oficina com aproximadamente 80 enfermeiras, coordenados por feministas. Observa-se, a partir daí, uma efervescência acerca desta área de estudo, a qual se reflete na publicação de vários livros, bem como na criação de núcleos de estudos e da articulação de redes com a participação de enfermeiras que o fazem, revendo e refazendo 
o seu pensar e agir cotidiano.

Apesar de nāo encontrarmos estudos que abordem o desenvolvimento da enfermagem sob a ótica do feminismo em suas diversificadas correntes filosóficas, os estudos analisados buscam na história de opressão e subserviência da mulher na sociedade, em particular nas esferas privada e pública, as implicaçōes especificas para a profissăo de enfermagem. Este discurso, emergente no Congresso Brasileiro de Enfermagem de 1979, mais explicitamente com Oliveira (1979) e Silva (1979), parece encontrar eco nos artigos posteriormente publicados, se configurando em uma nova área de estudos, ou seja, as relaçōes de gênero na enfermagem.

As publicações, de cunho reflexivo, que se seguem àquele Congresso se constituem muito mais como foro de denúncias e em instância de conscientização da condiçăo da enfermagem contemporânea, a partir das raizes da profissão e de sua caracteristica de inserção predominantemente feminina. Os discursos se repetem, evidenciando pouco avanço na problematização das questöes relativas ao desenvolvimento da profissão de enfermagem e às condições sociais das mulheres, inseridas em sociedade patriarcais.

Entretanto, algumas reflexões se destacam, como as de Coradini; Barbiani (1983) e Wright; Carneiro (1985), pelas contribuições acerca da evolução histórica da mulher e sua influência na enfermagem e repercussōes na comunidade da enfermagem.

No campo da pesquisa, podemos citar as desenvolvidas por Padilha (1991) e Meyer (1993). Padilha (1991), ao analisar a influência familiar e social de 117 enfermeiras, na escolha e exercício da enfermagem, verifica a existência da familia patriarcal, no que concerne as relaçōes familiares, tendo cada membro um papel determinado nesse contexto. A inserção da mulher nas universidades, no mercado de trabalho e na politica mostra-se como o caminho de escolha para estabelecer uma nova estrutura nas relaçōes familiares e sociais. Um aspecto de destaque é o fato da autora verificar que o futuro das relações homem-mulher, enfermeira-enfermeiro, enfermeira/o e equipe de saúde apresenta uma tendência transformadora positiva no decorrer da história. Embora a rigidez patriarcal ainda subsista, algumas rupturas nos papéis familiares são verificadas, o que mostra os indicios propulsores das transformaçōes que estão se operando na sociedade.

A constataçăo de Padilha (1991) se assemelha a de outras autoras do campo da psicologia (Marodin, 1997, Strey, 1997), tendo em vista a intensificação do repensar dos papéis da mulher e do homem na sociedade, na familia e no trabalho. Como bem assinala Marodin (1997), tais transformações são, em grande parte, fruto dos movimentos feministas, ao realçarem a necessidade de questionamento até então inquestionável, principalmente no que se refere aos estereótipos culturais dos papéis de gênero.

Meyer (1993), a partir de um estudo com 15 docentes, procura entender os determinantes históricos e sociais que fizeram da enfermagem uma profissão na qual se estabelece um sem número de requisitos que a enfermeira deve preencher e que extrapolam a competência técnica-cientifica, para que sejam reconhecidas como boa profissional. Em suas reflexōes destacam-se a relação da enfermagem com a doméstica e moralidade, e a relação mulher e trabalho. Embora muitas das questōes relativas a estas relaçōes tenham emergido anteriormente na literatura, Meyer amplia o discurso, explicitando o conceito de gênero e apoiando-se no pensamento de várias feministas brasileira e estrangeiras.

As questōes mais evidentes apontadas pelos estudos relacionam-se aos estereótipos da profissão, suas raizes religiosas e vocacionais, as quais são elegidas para explicar, as vezes parcialmente e outras quase que totalmente, o ponto prestigio da profissão na sociedade, a baixa remuneração e, a dupla jornada de trabalho, dentre outros aspectos. 
Contudo, muitas das reflexōes se mostram descontextualizadas dos quadros de reflexões e atuação da época, principalmente no que se refere as de outras áreas do conhecimento, sem a explicação de um referencial teórico relacionado à área de gênero. A trama teórica nas reflexões desta categoria aparece intimamente relacionada com a categoria seguinte de gênero e trabalho, a qual vem gradativamente ganhando espaço na literatura nos últimos anos.

\section{GÊNERO E TRABALHO}

A relação de gênero e trabalho não alcançou, ainda, uma posição de destaque nos estudos da enfermagem, mas podemos verificar um interesse crescente pelo tema na década de 90 , com predominância para os anos de 1996 e 1997. Embora possamos encontrar estudos, incluindo a categoria trabalho, publicados anteriormente a essa data, estes ocultam o sexo das/os profissionais da enfermagem, não problematizando esta diferenciação no trabalho. $\dot{E}$ interessante notar o interesse recente da enfermagem brasileira pelo trabalho da mulher, apesar de nos fins da década de 70 e inicio dos anos 80 já presenciarmos em algumas áreas do conhecimento, como é o caso da sociologia, um intenso debate politico e cultural sobre o trabalho feminino (Lobo, 1992). Este fato pode ter contribuido para alguns alertas na literatura, como os de Gomes (1986) e Steagall-Gomes; Mendes (1995), quando ressaltam que apesar das mulheres constituirem uma força de trabalho importante em todo o mundo, poucos estudos consideram as diferenças ligadas as sexo como objeto de investigação.

As pesquisas sobre gênero e trabalho na enfermagem apontam para um trabalho desvalorizado, e, portanto, invisivel, perpassado pela dominação, opressão e marginalização, e, além do mais, gerador de riscos à saúde. Destacamos aqui, o estudo de Lopes (1988), que analisa criticamente a relação gênero e trabalho, configurada na divisão sexual do trabalho, somada à perspectiva de classe. Em suas reflexöes, a autora destaca a enfermagem como ramo derivado e a serviço da medicina, a qual se caracteriza como prática subsidiária e subalterna como convém à manutenção da divisão social e sexual do trabalho. Segundo a autora, as bases ideológicas que têm levado a enfermagem e as enfermeiras a "servir" ao capitalismo, refletem as tendências históricas das mulheres a reproduzir a ideologia dominante na sociedade e a assimilação em sua própria conduta dos mitos masculinos a seu respeito (Lopes, 1998).

Petersen (1997), da área de Ciências Politicas, ao referir-se ao censo de 1980, evidencia que as principais profissōes femininas eram: empregadas domésticas (20\%), secretárias (15\%), professoras $(8 \%)$, comerciárias $(4,5 \%)$, e enfermeiras $(2,5 \%)$. Conforme a autora, essas profissōes dispōem de baixo prestigio e são precariamente remuneradas. Destaca por outro lado, que o fato de as mulheres ganharem menos explica por que hoje, quando o pais vive uma profunda crise econômica, estão abrindo-se espaços no mercado de trabalho para as mulheres, especialmente para as que têm formação universitária. $\mathrm{Na}$ opinião da autora, convém admitir mulheres com esta formaçāo porque, enquanto $28 \%$ dos homens com curso superior completo ganham mais de vinte salários minimos, apenas $7 \%$ das mulheres, na mesma situação, chegam a esse patamar salarial. Considerando os resultados do estudo de Padilha (1991), esta realidade se mostra frustante, principalmente para a enfermeira, tendo em vista que ela procura a enfermagem tendo como aspiração a melhoria salarial, ascensão profissional, aquisição de status e forma de sair do julgo familiar.

Ainda considerando a divisão sexual do trabalho, mais recentemente, os estudos de Progianti $(1996,1997)$ evidenciam nas relações sociais de gênero entre enfermeiras obstetras e médicos, a produção de subordinação através da divisão sexual do trabalho. Progianti (1997) constata que estas profissionais fazem politica e exercem formas de resistências-poder como aprenderam dentro do lar, sendo estas desvalorizadas socialmente.

No que se refere à invisibilidade do trabalho na enfermagem, este tem sido uma temática 
presente nos estudos analisados, podemos aqui citar os estudos de Pereira e Bellato (1996) e Pereira e Silva (1997). Contudo, muitos estudos reduzem o trabalho de enfermagem ao da enfermeira, o que evidencia a invisibilidade mantida em relação ao trabalho das outras categorias de enfermagem.

Esta rede de questöes teóricas, ao serem fundamentais nos estudos de gênero, tem também merecido a atenção de pesquisadoras de outras áreas. Rodrigues (1992) ao discutir o trabalho feminino a partir do lugar e imagem da mulher na indústria aponta a "invisibilidade" das mulheres quando se trata do tema "tecnologia e divisão do trabalho" e define a apropriação masculina da tecnologia. Deste modo, ela verifica algo que é incessantemente reiterado e que é próprio de um todo social e de todas as sociedades: a diferenciação sexual e a dominação masculina. Neste estudo, Rodrigues aponta algumas caracteristicas que transpassam todas as esferas (familia, sociedade, fábrica), o mesmo trabalho social: invisibilização do trabalho feminino, invisibilização da qualificação feminina e, consagração da diferença sexual, ai embutida a superioridade masculina.

O estudo de Castro e Lavinas (1992), ao buscar situar o estado da produção teórica sobre mulher e trabalho na década de 80 , no Brasil, através de textos apresentados no Grupo de Trabalho - GT Mulher e Força de Trabalho da ANPOCS ${ }^{5}$, apontam o trabalho feminino como intermitente, logo instável, altamente desqualificado, bastante concentrado no terciário, notadamente no ramo dos serviços não assalariados.

Neste estudo, as autoras evidenciam aspectos pouco animadores nos últimos vinte anos, tais como: aumento das desigualdades salariais entre os sexos, manutenção da segregação ocupacional, recriação de guetos de ocupação feminina, agravamento das discriminaçōes no plano dos direitos sociais, generalização da dupla jornada de trabalho entre as mulheres dos setores populares. As mulheres negras, chefes de familia, aparecem como o segmento social mais discriminado. Considerando-se as categorias sócio-profissionais, este triste troféu fica por conta das empregadas domésticas, das trabalhadoras rurais e das fábricas (Castro; Lavinas, 1992). Soma-se a estas constatações, outra condição grave, relativa ao fato das mulheres serem as mais atingidas pelo desemprego (Seade, 1997).

Ao considerarmos a relação gênero, saúde e trabalho, os poucos estudos da enfermagem acentuam o agravamento desta realidade. Lopes (1992) constata a realidade de um trabalho explorado, gerador de tensões, com carga excessiva de trabalho, mal remunerado e com pouquissimo poder de barganha frente a classe dominante.

Parte das constataçōes de Lopes são apoiadas pelo estudo de Aquino et al . (1993), ao relacionar saúde e trabalho de mulheres profissionais de enfermagem em hospital público de Salvador. Aquino et al. (1993) constataram que tanto o grupo de enfermeiras como de auxiliares de enfermagem apresentavam excessivas jornadas de trabalho profissional. Contudo, as auxiliares são duplamente penalizadas pelo acúmulo de trabalho doméstico, o que contribui para suas piores condições de saúde. Deste modo, as autoras encontraram, especialmente para as auxiliares de enfermagem, elevada incidência de problemas agudos e crônicos.

No campo da docência, Mauro (1997), em seu estudo, verifica condições de trabalho desfavoráveis que levam a fadiga, tanto por parte das docentes enfermeiras como não enfermeiras. Neste sentido, a autora alerta para a necessidade de valorizaçăo na relação saúde versus trabalho e de adoção de medidas para evitar a ocorrência das patologias do trabalho na docente mulher.

${ }^{5}$ ANPOCS - Associação Nacional de Pós-Graduação e Pesquisa das Ciências Sociais. 
Apesar de um número pouco maior de pesquisas nesta categoria, constatamos o estado incipiente dos estudos na enfermagem; quando comparado aos estudos de outras áreas do conhecimento. Por outro lado, destacamos a ausência de estudos relacionando gênero e mercado de trabalho, bem como evidenciando o ciclo de vida produtivo das trabalhadoras de enfermagem. Outra questão de destaque é a quase ausência de estratégias de enfrentamento desta realidade, evidenciadas nos estudos.

Podemos também observar que as várias constatações, principalmente relativas a desvalorização do trabalho da enfermagem, săo apoiadas por estudos de outras áreas. Deste modo, a crise que a enfermagem, bem como outras profissões essencialmente femininas, têm vivenciado baseia-se, em parte, na visão reducionista e separativista do paradigma da modernidade, o qual tem contribuido para a centralidade do modelo tradicional de ciência, assim como para a hierarquia do poder. Visăo esta, que tem reforçado o sistema patriarcal, com conseqüente manipulação e exploração das mulheres e da natureza (Silva, 1997). Conseqủentemente, as mudanças requeridas perpassam pela própria transformação do paradigma vigente. Transformação esta, que apesar de estar em seus passos iniciais, já nos faz antever novos horizontes no processo das relaçōes sociais.

A análise desta categoria de gênero aponta para as grandes contribuiçőes dadas pelos estudos até aqui efetuados, mas ao mesmo tempo as imensas lacunas ainda existentes. A realidade com que nos deparamos e a necessidade urgente de transformaçōes, com vistas a uma maior valorização do trabalho de enfermagem e da melhoria da qualidade de condições deste, nos levam a considerar esta uma área prioritária nos estudos em enfermagem. Fica claro, que não se pode enveredar por este terreno ingreme, sem considerar a dimensão relacional de gênero, quer como categoria analitica, quer enquanto processo social, esperando que os estudos possam servir para revitalizar os elos entre a prática teórica e a prática de transformação.

\section{GÊNEROE SAÚDE}

Desde meados dos anos 70 vem crescendo, no Brasil, o interesse pelas questōes da mulher. $\mathrm{Na}$ área da saúde, a década de 80 é particularmente singular, pelos inúmeros seminários, cursos, encontros e publicaçōes, muitos desses promovidos pelo movimento feminista, contemplando, inicialmente, os estudos da mulher e, posteriormente, os estudos de gênero. Nesta década também, por influência do movimento feminista no espaço acadêmico, são criados grupos de trabalho em praticamente todas as associaçōes nacionais de pós-graduaçăo em Ciências Humanas ${ }^{6}$ (Aquino et al., 1995). Como resultado, muitas das proposiçőes emergentes tiveram contribuição inegável na definição de politicas sociais de interesse das mulheres, com especial ênfase para o PAISM -Programa de Assistência Integral à Saúde da Mulher (Aquino, 1998).

Essa vitalidade, entretanto, não se expressou com a mesma intensidadeno âmbito acadêmico em geral (Aquino, et al., 1995) e mais especificamente no da enfermagem. Tomando como base o universo deste estudo, a análise da produção acadêmica na enfermagem evidencia a supremacia de estudos relativos à saúde da mulher, ainda na perspectiva biológica e na fase reprodutiva, buscando compreender a mulher em um mundo puramente feminino, sem relação com o masculino. Em outras áreas do conhecimento, o periodo que compreende o final de 80 e início de 90 marca uma forte sinalização para substituir os

${ }^{6}$ Entre outras, a ANPOCS (Ciências Sociais, a ABA (Antropologia), ABEP (Estudos Populacionais), ANPUH (História), ANPOLI (Letras e Literatura), ABRALIC (Literatura Comparada), ABET (Trabalho), ANPED (Educação), ABRAPSO (Psicologia Social). 
estudos da mulher pelos de gênero, para valorizara a diferença, apontar os poderes (ainda que "menores") das mulheres, não sobreenfatizar o poder masculino, desconfiar das grandes explicações, criticar o gueto, dentre outros aspectos (Machado, 1992). Na enfermagem, entretanto, o pequeno número de publicaçőes, resultante, predominantemente de pesquisas, concentra-se, em sua grande maioria, no ano de 1997, mostrando ser recente o interesse da enfermagem em discutir gênero e saúde.

Dentre as temáticas de destaque, encontram-se: o processo saúde-doença da mulher (Fonseca, 1997a, Mandú; Silva, 1997, Thompsom, 1997), de jovens universitárias (Fonseca, 1997b) e mais especificamente da AIDS (Xavier, 1996). Neste contexto, certas perspectivas de análise apontam para os métodos contraceptivos (Ferreira et al., 1997); os significados do exame ginecológico (Lopes, 1994) e do desmame precoce para as mulheres (Almeida, 1997); e a consulta de enfermagem à mulher (Gomes, 1996).

A incorporação da relação de gênero nas discussões relativas à saúde da mulher se traduz em uma ruptura nos discursos, até então existentes, redimensionando as perspectivas de análise, por tornar visivel outro determinante da qualidade de vida da população feminina. Neste sentido, destacam-se nos discursos denúncias contra uma assistência situada estritamente na resolução pragmática das questões da doença, associada a interpretação mecanicista e a-histórica do processo saúde-doença, não havendo, portanto, nenhum tipo de aderência com as especificidades da realidade de saúde coletiva. Segundo Fonseca (1997b), esta forma de interpretação contribui para a universalização da assistência às necessidades da população e ao atendimento às mesmas por não estabelecer as conexões existentes entre a maneira como a sociedade está organizada na determinação do processo saúde-doença e dos demais processos a ele relacionados. Deste modo, como bem assinala a autora, é mantida a invisibilidade do gênero como um dos determinantes do processo saúde-doença. Outras constatações também evidenciam a forte influência do modelo patriarcal no sistema de assistência à saúde da mulher, resultando, assim, em relações dificeis e conflitantes entre uma clientela passiva e subordinada e a figura autoritária do médico. Todos estes fatos, somados às inúmeras violências a que são submetidas nos serviços de saúde, têm sido motivo de denúncias por parte dos grupos de defesa pelos direitos da mulher, como o Sempre-Viva Organização Feminista (SOF) (Lopes, 1994). Estas violências se agravam quando consideramos as mulheres pertencentes às classes sociais mais desfavorecidas. Segundo Fonseca (1997a), estas mulheres apresentam um perfil reprodutivo biológico determinado pela dupla condição de subalternidade, de classe e de gênero.

Face ao exposto, fica evidente em alguns estudos a necessidade de trabalhos educativos que auxiliem as mulheres a desenvolver uma consciência mais critica em relação ao seu processo saúde-doença e às formas como prevenir ou controlar suas manifestações. Neste sentido, concordando com Fonseca (1997a) de qualquer proposta deve não só levar em conta o pretexto mais amplo na qual ela de insere mas também resultar de uma abordagem multidisciplinar, pois foge completamente às possibilidades de apenas uma disciplina, levá-la a cabo.

A escassez de estudos relacionando gênero e saúde torna evidente imensa lacuna e os desafios com que se depara a comunidade cientifica da enfermagem. Esta categoria, ao ser prioritária nas agendas de pesquisas, abre uma imensa de objetos protenciais de investigação, os quais além de ampliar os conhecimentos existentes, poderão contribuir sobremaneira para a melhoria da qualidade de vida. 


\section{GÊNEROE EDUCAÇĀO}

A década de 80 se caracteriza como momento impar para a enfermagem brasileira, pois marca um novo repensar sobre as bases da profissão de enfermagem, o que traduz no conteúdo dos diversos livros publicados nesta década. Contudo, ao analisarmos os artigos publicados nos periódicos em questão, constatamos a escassez de estudos que explicitem, em suas análises, a educação na perspectiva das relações de gênero. Os estudos nesta categoria, ao emergirem no inicio da década de 90 , se apoiam em reflexōes já presentes na década de 80 , e enfatizam aspectos ligados a enfermagem enquanto profissão essencialmente feminina, aliada aos antecedentes religiosos e vocacionais da enfermagem, a partir de uma abordagem ainda predominantemente interna a profissão. Deste modo, os discursos evidenciam pouco avanço teórico, bem como de estratégias de enfrentamento desta realidade.

Alguns estudos se destacam, a exemplo dos de Meyer (1992, 1993) e Lunardi (1993). Meyer (1992) enfoca a formação morale de atitudes que se dá no processo de formação das enfermeiras e as suas relações com a manutenção e reprodução de relações de poder, de gênero e de classe no interior da profissão. A autora dfetecta a influência do pensamento liberal e do modelo tecnicista de ensino na concepção de educação e no desempenho profissional, reforçados pelo modelo patriarcal. Verifica que as tentativas de mudanças são levadas a cabo por pequenos grupos, no sentido de encontrar formas mais criticas, mais abrangentes, a partir do contexto sócio-econômico-cultura para a conduçăo do ensino. Contudo, prevalecem os problemas gerados no âmago da trajetória histórica-social da profissão e das politicas educacionais que têm norteado o ensino brasileiro e, mais especificamente, o da enfermagem.

Lunardi (1993), ao eleger como objeto a formação disciplinar das enfermeiras, partir do conceito de Foucalt, busca, através da analise e reflexão das práticas do cotidiano e da história da profissão, maior compreensão e entendimento das relações e interconexōes entre a educação das enfermeiras, sua submissão e (im)possibilidade de um contra-poder no exercicio da profissão. Conforme a autora, o ensino de enfermagem adquire uma forma (disciplinar), expressa principalmente por instrumentos de controle do corpo, do tempo, da busca de padronização, da presença do olhar supervisor e das sançōes disciplinares, que passam a se constituir em conteúdo, em um "saber" necessário e inerente à prática.

É evidente a reprodução do modelo patriarcal no ensino da enfermagem, como instância de dominação que atravessa os vários espaços sociais, tanto no interior da profissão, como fora dela. Contudo, já podemos constatar mudanças nesta realidade, como exemplifica Fonseca (1995). A autora expressa sua satisfação ao detectar mudança na visão das alunas de enfermagem, tanto em nivel de graduação como de pós-graduação, em relação ao processo existencial da mulher, quando é introduzida a reflexão sobre a situação social da mulher, a partir da perspectiva de gênero. Segundo a autora, esta abordagem tem favorecido a elas a compreensão do processo saúde-doença como socialmente determinado, e a forma que ele assume, quando visualizamos sob um recorte analitico que diferencia homens e mulheres socialmente, a partir da maneira como a sociedade se organiza no processo de reprodução social. Por serem mulheres, afirma a autora, tipo de reflexão propicia a ampliação da sua consciência em relação à própria vida, ao corpo, às relações que estabelecem com os homens (médicos, companheiros, maridos, etc.), com o trabalho, e também, com o próprio processo de construção do conhecimento. Consequeentemente, a inclusão de disciplinas sobre relaçōes de gênero nos currículos de enfermagem é fundamental e urgente. 


\section{GÊNERO E FEMINISMO}

Reafirmando a constatação de Pereira (1996), podemos dizer que são poucos os trabalhos tendo como categoria gênero e feminismo. Embora vários trabalhos sob a ótica de gênero utilizem pensamentos de autoras ${ }^{7}$ de outras áreas, no processo de reflexão e análise, muitas delas declaradamente feministas, eles não explicitam esta categoria de análise. Por outro lado, não encontramos nenhum artigo, em que a/s autora/s se autodenominasse/m feminista/s. O pequeno universo das autoras citadas nos leva a supor um certo desconhecimento, por parte das enfermeiras, acerca dos inúmeros trabalhos publicados recentemente na área, no âmbito nacional e internacional. Destacamos aqui o fato da quase totalidade de autoras/es citadas/os serem brasileiras e mesmo quando são estrangeiras/os, os estudos são traduções dos originais.

O primeiro artigo sobre o assunto data de 1993 (Sardenberg; Costa) ${ }^{8}$, mas é somente nos anos de 1996 e 1997, que se concentram a maioria dos artigos publicados. O desinteresse pelos estudos feministas na enfermagem brasileira se contrapõe ao interesse crescente na enfermagem norte-americana, em que as diversas vertentes feministas têm oferecido valiosas contribuições para a prática, ensino e pesquisa (Chinn, 1994). Em um estudo desenvolvido com base na literatura da enfermagem norte-americana, no periodo de 1971 a 1993, Peggy Chinn (1994) detectou a influência de inúmeros pressupostos feministas, desafiando as direções da construção do conhecimento, das tradicionais formas de investigação e dos prevalentes paradigmas na educação e prática de enfermagem. Dentre as vertentes teóricas feministas que influenciaram estes estudos, Chinn encontrou: feminismo liberal, na década de 70 , feminismo cultural, na década de 80 , feminismo críticosocial na década de 90 , eco-feminismo e feminismo pós-moderno ainda emergentes. Contudo, o feminismo contemporâneo apresenta-se qual um caleidoscópio em suas diversificadas vertentes filosóficas, muitas destas ainda não utilizadas na enfermagem (Silva, 1996).

Utilizando o pensamento da historiadora Margareth Rago (1997), nos perguntamos: como explicar que as inúmeras conquistas, como a entrada maciça das mulheres na esfera pública, sobretudo nos últimos 30 anos, a decorrente feminização da cultura, a evidente transformação nas relações de gênero, não corresponda a uma crescente valorização do feminismo, e mesmo a uma incisiva adesão a ele, seja se o considerarmos enquanto um conjunto de idéias que reivindicam os direitos da mulher, seja se nos referirmos às práticas e lutas que eclodiram e vêm eclodindo na sociedade? Por que nós mulheres-enfermeiras parecemos não reconhecer as conquistas relativas às diversificadas possibilidades abertas especialmente nas últimas três décadas, como um resultado das pressões e lutas colocadas pelo feminismo?

Poderia tal fato ser decorrência dos estereótipos associados às feministas, que vêm de longa data, e não apenas dos anos 1970, definindo-as como "machas, feias e mal-amadas"? (Rago, 1997); ou será pelo próprio desconhecimento, por parte das enfermeiras, do que consiste o feminismo, das suas diversificadas vertentes filosóficas e contribuiçōes para a enfermagem?

\footnotetext{
${ }^{7}$ Destacamos aqui algumas das autoras mais citadas: Simone de Beauvoir (1980), Cristina Bruschini (1978, 1979, 1985, 1992), Rose M. Muraro (1983, 1991, 1992), Nancy Chodorow (1979, 1990), Heleith I. B. Saffioti (1979, 1981, 1982, 1994), Elisabeth Badinter (1986), Elena Gianini Belotti (1987), Eva Blay (1995), Jane Flax (1991), Joan Scott (1990).

${ }^{B}$ Estas autoras são professoras da Faculdade de Filosofia e Ciências Humanas da UFBA.
} 
Como bem coloca Rago (1997), è certo que nem todas as mudanças positivas e negativas devem ser atribuidas ao feminismo, por outro lado, também não podemos simplesmente ignorar um movimento social, politico e intelectual que teve um profundo impacto na sociedade brasileira e no mundo, de um modo geral. Ao lado de outros movimentos sociais dos anos sessenta e setenta, como o movimento negro, especialmente o norteamericano, o feminismo adquire uma enorme importância ao questionar a organização sexual, social, politica, econômica e cultural de um mundo predominantemente hierárquico, autoritário, masculino, branco e excludente.

Não podemos negar que na história da enfermagem brasileira, encontramos diversas mulheres, que, dentre outros aspectos, reivindicam o direito à educaçăo, ao trabalho e à participação no mundo público em igualdade, questionaram as relações de poder na esfera privada e pública, lutaram pelo espaço da enfermagem no conjunto das relações sociais, e, assim, contribuiram muito para o avanço da profissăo. Muitas delas, embora não se auto-denominassem feministas, tiveram como bandeira de luta os principios feministas. Por que o feminismo ficou invisivel na enfermagem? Esta é uma pergunta que está ainda por ser respondida. Muitos aspectos de nossa história ainda estão por serem resgatados e valorizados. Dentre eles, a história de lutas destas mulheres, tanto na esfera pública e privada.

Tomando como base os artigos analisados, as relaçöes estabelecidas apontam para feminismo e educação (Waldow, 1994), feminismo e trabalho (Pereira; Bellato, 1995, 1996; Pereira; Silva, 1997; Progianti, 1996), feminismo e pesquisa (Silva, 1997), feminismo e politicas de atenção à saúde da mulher (Nascimento, 1992). Constatamos uma tendência explicita para as vertentes feminista pós-moderna (Pereira; Bellato, 1996, Silva, 1997) e feminista marxista, modificada para incorporar algumas considerações de outras teorias, como do patriarcado (Fonseca, 1997b).

Algumas vertentes são abordadas, ligeiramente, em dois artigos, como as vertentes liberal feminista, marxista, radical socialista (Pereira, 1996, Waldow, 1996). De inegável valor é o artigo de Sardenberg e Costa (1993), que delineia, de forma critica, a trajetória do feminismo no Brasil, dando especial atenção para o significado, alcance e rumos das lutas feministas na nossa sociedade, nos últimos quinze anos.

Destacamos também o fato do feminismo estar merecendo a atenção do sexo masculino, na enfermagem. Álvaro Pereira (1996), ao apresentar as contribuições do paradigma feminista ao conhecimento e à prática de enfermagem, sugere que: 1) as escolas de enfermagem reavaliem os seus curriculos em direção a esse paradigma; 2) os grupos de pesquisadores utilizem as teorias feministas em qualquer trabalho que tenham que explicar as relaçŏes de trabalho da enfermeira, na esfera pública e privada; 3 ) as pesquisadoras sejam arrojadas no sentido de redirecionar o foco de suas pesquisas para a mulher, com a visão de ciência da mulher e dos métodos de investigação aceitos por ela, sem medo de testálos e de divulgá-los como feministas.

Os trabalhos analisados evidenciam que há por parte de várias autoras um certo desconhecimento das vertentes filosóficas feministas, na medida em que abordam o feminismo de modo geral, sem explicitar a vertente adotada. Assim, como gênero, a opção pelo conceito feminismo implica em decisão de ordem epistemológica, implica em opçăo teórica. Isto porque, as diversas vertentes filosóficas feministas apresentam diferentes e conflitantes pressuposiçōes teóricas. Contudo, cabe ressaltar que apesar das diferenças, as teóricas feministas compartilham quatro interesses, como apontam Jaggar e Rothenberg (1984): 1) procuram entender a natureza de gênero de virtualmente todas as relações sociais e institucionais; 2) as relações de gênero são construidas como problemáticas e relacionadas a outras desigualdades e contradiçōes na vida social; 3) as relaçōes de gênero não são vistas como naturais ou imutáveis, mas como produções históricas e sócio- 
culturais, sujeitas a desconstrução; 4) teóricas feministas tendem a ser explicitamente politicas em suas defesas de mudança social.

O feminismo, em sua diversidade teórica, oferece importantes contribuições para a enfermagem, principalmente por se traduzir em prática de transformação, de socialização do poder e de privilégios nas relações sociais. Como se refere Rago (1997), o feminismo aponta para a critica da grande narrativa da história, mostrando as malhas de poder que sustentam as redes discursivas, denunciando e criticando; logo deve ser pensado e lembrado.

\section{ALGUMAS CONSIDERAÇÕES}

Ao buscarmos, neste estudo, avaliar o estado da arte das relações de gênero na enfermagem brasileira, tomando como base dez periódicos nacionais, no periodo de 1955 a 1997/1, apontamos as categorias centrais para as quais convergiram a atenção das/os autoras/es, ou seja, gênero e determinantes históricos e sociais no desenvolvimento da profissão de enfermagem, gênero e trabalho, gênero e saúde, gênero e educação, gênero e feminismo. Merece também destaque o fato de estar emergindo na literatura outras importantes categorias, tais como, gênero e cuidado, gênero e familia, gênero e violência. Dada a impossibilidade de capturar, neste estudo, a abrangência das categorias, em suas múltiplas e diversificadas perspectivas de análise, buscamos apresentar uma visão mais geral, o que, de certa forma, limitou nosso percurso pelas suas especificidades. Contudo, podemos constatar que, apesar da recente incorporação das relaçōes de gênero na enfermagems, a literatura já aponta uma multiplicidade de abordagens, evidenciando um redimensionamento no processo construção do conhecimento em nossa disciplina profissional. Neste sentido, a adoção e a exploração das relaçōes de gênero se constituem em requisito fundamental para a construção e avanço de uma epistemologia inovadora em enfermagem.

ABSTRACT: The aim of this study was to analyze the gender categories, in the gender studies in Brasilian Nursing. Using an exploratory approach, we analyze the articles in this area, published en ten Brasilian journals, from 1955 through 1997/1. Based on the analysis of the texts, the main categories to what the attention of the authors converged, were: gender and, historical and social determinants in the nursing profession development, gender and work, gender and health, gender and education, gender and feminism. Other important perspectives, less emphasized but emerging in the nursing literature, were: gender and caring, gender and family, gender and violence.

KEY WORDS: gender, nursing.

RESUMEN: Este estudio tuvo como objetivo analizar las categorias de género, a partir de periódicos que abordan este factor dentro de la enfermeria brasilera. Usando una metodologia exploratoria, analisamos los articulos al respecto de esa área publicados en diez periódicos nacionales de enfermeria, en el periodo comprendido entre 1955 y 1997/1. Con base en el análisis de los textos, las principales categorias hacia las cuales convergió la atención de los autores fueron: género y determinantes históricos y sociales en el desarrollo de la profesión de enfermeria, género y trabajo, género y salud, género y educación y género y femenismo. Otras perspectivas importantes, a las que se dió menos énfasis, pero que, sin embargo, aparecen en la literatura de enfermeria fueron: género y familia, género y violencia.

PALAVRAS LLAVE: genero, enfermeria. 


\section{REFERÊNCIAS BIBLIOGRÁFICAS}

AQUINO et al. Saúde e trabalho de mulheres profissionais de enfermagem em um hospital público de Salvador, Bahia, Rev. Brasileira de Enfermagem, v.46, n. 3/4, p. 245-256, 1993.

AQUINO et al. Gênero e saúde: estado atual da produçāo do conhecimento epidemiológico no Brasil, 1995. Mimeo.

ALMEIDA, M. S. Sentimentos femininos, o significado do desmame precoce para as mulheres. Rev. Texto e Contexto-Enfermagem, v.6, n.1, p.260-275, 1997

BARDIN, L. Análise de conteúdos . Lisboa: Ediçōes 70, 1979.

CASTRO, M.G.; LAVINAS, L. Do feminismo ao gênero: a construçăo de um objeto. In: COSTA, A. de O.; BRUSCHINI, C. (Orgs.). Uma questão de gênero. Rio de Janeiro: Rosa dos Tempos, 1992. P. 217-251.

CHINN, P. L. Feminism and nursing. Annual Review of Nursing Research, May 30, 1994. In press.

CORADINI, S.R.; BARBIERI, R. O profissional enfermeira frente as influências da evoluçāo histórica da mulher. Rev. Brasileira de Enfermagem , v.36, p.246-254, 1983.

COSTA, A. de O., BRUSCHINI, C. (Orgs.). Uma questão de gênero. Rio de Janeiro: Rosa dos Tempos, 1992, p. 9-14: Introduçāo.

FERREIRA, S. L., et al. Opiniöes de mulheres e homens a respeito da utilizaçäo dos métodos contraceptivos. Rev. Texto e Contexto-Enfermagem, v.6, n.1, p. 246-259, 1997.

FONSECA, R.M.G.S. da. A educaçäo e o processo de inclusão-exclusăo social da mulher: uma questão de gênero? Rev. Brasileira de Enfermagem, v.48, n.1, p. 51-59, 1995.

Espaço e gênero na compreensāo do processo saúde-doença da mulher brasileira. Rev. Latino-Americana de Enfermagem, v.5, n.1, p. 5-13, 1997a.

Classe social, gênero e processo saúde-doença: perfil sócio sanitário de jovens universitárias. Rev. Baiana de Enfermagem, v.10, n.12, p. 71-94, $1997 \mathrm{~b}$.

GOMES, D.L.S. A mulher, seu trabalho e as implicaçōes em sua saúde. Rev. Paulista de Enfermagem, v.06, n.2, p. $91-96,1986$.

GOMES, M. L. Quando sāo mulheres (clientes e enfermeiras) na consulta de enfermagem. Rev. Enfermagem UERJ, ediçăo extra, p.109-112, 1996.

HOLLANDA, H.B. de. Os estudos sobre mulher e literatura no Brasil: uma primeira avaliaçăo. In: COSTA A. DE O.; BRUSCHINI, C. (Orgs.). Uma questão de gênero. Rio de Janeiro: Rosa dos Tempos, 1992. p.54-92.

JAGGAR, A.M.; ROTHENBERG, P. Feminist framework: alternative theoretical accounts of relations between women and men. New YorkL. McGraw-Hill, 1984.

LIMA, M.J. Gênero, poder e saber. Rev. Enfermagem UERJ, v.3, n.1, p.93-100, 1995.

LOBO, E.S. O trabalho como linguagem: o gênero do trabalho. In: COSTA, A. DE O.; BRUSCHINI, C. (Orgs.). Uma questão de gênero. Rio de Janeiro: Rosa dos Tempos, 1992. p.252-265.

LOPES, M.J. O trabalho da enfermeira: nem público, nem privado, feminino, doméstico e desvalorizado. Rev. Brasileira de Enfermagem, v.41, n. 3/4, p. 211-217, 1988.

LOPES R.L.M. A mulher vivenciando o exame ginecológico na prevençāo do câncer cérvico-uterino. Rev. Enfermagem UERJ, v.2, n. 2, p. 165-170, 1994.

LOURO, G.L. Nas redes do conceito de gênero. In: LOPES, M.J.M.; MEYER, D.E.; WALDOW, V.R. (Orgs.) Gênero e saúde. Porto Alegre: Artes Médicas, 1996. p.7-18.

Gênero, sexualidade e educaçäo: uma perspectiva pós-estruturalista Petrópolis: Vozes, 1997.

LUNARDI, V.L. Relacionando enfermagem, gênero e formaçăo disciplinar. Rev. Brasileira de Enfermagem, v.46, n. 3/4, p. 286-295, 1993.

MACHADO, L.Z. Feminismo, academia e interdisciplinaridade. In: COSTA, A. DE O.; BRUSCHINI, C (Orgs.). Uma questăo de gênero. Rio de Janeiro: Rosa dos Tempos, 1992. p.24-38.

MANDU, E.N.T.; SILVA, G.B. da. A saúde-doença no olhar de mulheres. Texto e Contexto Enfermagem, v.6, n.1, p. 219-243, 1997.

MARODIN, M. As relaçōes entre o homem e a mulher na atualidade. In STREY, M.N. (Orgs.) Mulher - estudo de gênero. São Leopoldo-RS: UNISINOS, 1997. p.9-18.

MAURO, M.Y.C. Saúde da mulher docente: condiçōes de trabalho e fadiga. Rev. Enfermagem UERJ, v. 5, n. 2, p. $419-438,1997$.

MEYER, D.E.E. Ao olhar-se no espelho, a enfermeira não tem gostado da imagem que ai vê refletida. Rev. Brasileira de Enfermagem, v.45, n. 2/3, p. 176-182, 1992.

Por que só mulheres? O gênero da enfermagem e suas implicaçōes. Rev. Gaúcha de Enfermagem, v.4, n. 1, p. 45-52, 1993.

NASCIMENTO, E.R. do. Politica de atenção à saúde da mulher no Brasil: historicamente a quem se destina? Rev. Baiana de Enfermagem, v.5, n. 1, p. 79-86, 1992. 
OLIVEIRA, M.I.R. de. Enfermagem e estrutura social. IN: Congresso Brasileiro de Enfermagem, 31. Fortaleza, 1976. Anais... Fortaleza: ABEn, 1979, p.9-26.

PADILHA, M.I.C de S. O resgate das raizes: a influência da formação familiar e social na escolha e exercicio da enfermagem. Rev. Brasileira de Enfermagem, v.44, n. 1, p. 30-35, 1991.

PEDRO, J.M. Relaçōes de gênero na pesquisa histórica. Rev. Catarinense de História, n. 2, p. $35-44,1994$

PEREIRA, A. Contribuição do paradigma feminista ao conhecimento e a pràtica da enfermagem. Rev. Cogitare Enfermagem, v.1, n. 2, p.57-63, 1996.

PEREIRA, W.R.; BELLATO, R. O trabalho da enfermagem: uma abordagem sob a perspectiva da teoria feminista. Rev. Texto e Contexto - Enfermagem , v.4, n.1, p. 66-82, 1995.

O trabalho da enfermeira: a pertinência da categoria analitica do gênero para o seu estudo. Rev. Brasileira de Enfermagem, v.49, n.4, p.485-496, 1996.

PEREIRA, W.R.; SILVA, G.B. da. A mulher, o trabalho e a enfermagem profissional: algumas reconsideraçōes sob a ótica do gênero. Rev. Texto e Contexto - Enfermagem, v.6, n.1, p. 18-32, 1997.

PETERSEN, A.T. Homens e mulheres: enfim, as desigualdades estão acabando? In: STREY, M.N. (Orgs.) Mulher-estudos de gênero . Săo Leopoldo-RS: UNISINOS, 1997, p.19-28.

PROGIANTI, J.M. A divisäo sexual do trabalho de enfermeiras obstetras que assistem à parturiente. Rev. Enfermagem UERJ, v.4, n. 2, p. 135-141, 1996.

Enfermeiras obstetras: estratégias de resistência à opressão masculina.

Rev. Enfermagem UERJ, v.5, n.2, p.469-474, 1997.

RAGO, M. Adeus ao feminismo? Feminismo e (pós) modernismo no Brasil. Cademo AEL, UNICAMP, $1995 / 2$ a $1996 / 1, p .11-43,1997$.

RODRIGUES, A.M. Lugar e imagem da mulher na indủstria. In: COSTA, A. DE O.; BRUSCHINI, C. (Orgs.). Uma questão de gênero. Rio de Janeiro: Rosa dos Tempos, 1992. p.266-288.

ROSENBERG, F. Educação formal e mulher: uma balança parcial da bibliografia. In: COSTA, A. DE O.; BRUSCHINI, C. (Órgs.). Uma questão de gênero. Rio de Janeiro: Rosa dos Tempos, 1992. p.151-182.

SAFFIOTI, H.I.B. Rearticulando gênero e classe social. In: COSTA, A. DE O.: BRUSCHINI, C. (Orgs.). Uma questão de gênero. Rio de Janeiro: Rosa dos Tempos, 1992. p.183-215.

SANDENBERG, C.M.B.; COSTA A. A. Feminismo e feministas. Rev. Baiana de Enfermagem , v.16, n.2, p.5-29, 1993.

SCOTT, J.W. Gender and the politcs of History. New York: Columbia University, 1988.

Gênero: uma categoria útil de análise histórica. Rev. Educação e Realidade. Porto Alegre, v.16, n.2, p.5-22, 1990.

SEADE (Secretaria de Economia e Planejamento do Estado de São Paulo). Mulheres em dados. São Paulo, 1997.

SILVA, G.B. da. Desenvolvimento da Enfermagem: correlação dos problemas da profissão e da mulher na sociedade. In: Congresso Brasileiro de Enfermagem, 31. Fortaleza, 1979. Anais ... ABEn: Fortaleza, 1979, p. 27-32

SILVA, A. L. da. As diferentes vozes no feminismo. In: Encontro Fazendo Gênero, 2 Florianópolis, 1996.

O feminismo pós-moderno e a pesquisa: implicações para a enfermagem. Rev. Texto e Contexto - Enfermagem, v.6, n.1, p.66-83, 1997.

Cuidado Tridimensional: um paradigma emergente . Pelotas: Ed. Universitária - UFPEL; Florianópolis: Programa de Pós-Graduaçăo em Enfermagem -UFSC, 1997.

STEAGALL-GOMES, D.L.; MENDES, I.J.M. A força de trabalho da mulher. Acta Paulista de Enfermagem, v. 8, n.1, p.61-74, 1995.

STREY, M.N. A mulher, seu trabalho, sua familia e seus conflitos. In: - estudos de gênero. Sāo Leopoldo-RS: UNISINOS, 1997, p.59-78

THOMPSON, J.E. A mulher no contexto da saúde, do trabalho e da sociedade. Rev. Enfermagem UERJ, v. 5 , n.1, p. 391-394, 1997.

XAVIER, I. de M. Cidadania, gênero e saúde: a mulher e o enfrentamento da AIDS. Rev. Enfermagem UERJ, edição extra, p.89-100, 1996.

WALDOW, V.R. Uma experiência com pedagogia feminista. Rev. Texto e Contexto - Enfermagem, v.3, n.1, p.102-115, 1994.

Mecanismos de opressāo: uma questão de gênero. Rev. Cogitare Enfermagem, v.1, n.12 p.64-69, 1996.

WRIGHT, M. da G.M., CARNEIRO, A . O espaço da mulher brasileira e o espaço da enfermeira brasileira. Rev. Brasileira de Enfermagem, v.38, n.1, p.55-62, 1985. 